\title{
Breath condensate ammonium is lower in children with chronic asthma
}

\author{
G. MacGregor*, S. Ellis", J. Andrews", M. Imrie*, A. Innes*, \\ A.P. Greening* and S. Cunningham ${ }^{\#}$
}

ABSTRACT: Exhaled breath condensate $\mathrm{pH}$ and ammonium reflect asthmatic status and acute exacerbations in adults. The aim of this study was to assess whether $\mathrm{pH}$ and ammonium could reflect asthma and its severity in children.

The current study comprised two parts: 1) a cross-section of 74 children with asthma (median age $10.5 \mathrm{yrs}$ ) compared with 47 healthy controls (median age $10 \mathrm{yrs}$ ); and 2) longitudinal assessment of eight children (mean age $\mathbf{8 . 5}$ yrs) admitted with asthma exacerbation. Condensate $\mathrm{pH}$ and ammonium were compared with clinical observations.

In the cross-sectional part of the study, lower per cent forced expiratory volume in one second was associated with more symptoms and treatment. There was no significant difference between median $\mathrm{pH}$ in children with stable asthma (6.05) compared with controls (5.90). Ammonium was significantly lower in children with asthma (median $258 \mu \mathrm{M}$ ) compared with controls (median 428 $\mu \mathrm{M})$. No association was found between ammonium or $\mathrm{pH}$ and lung function or symptom-free days. In the longitudinal study, significant improvements in oxygen saturation and respiratory rate with treatment of an acute exacerbation were not reflected by changes in $\mathrm{pH}$ or ammonium.

In conclusion, $\mathrm{pH}$ does not appear to reflect disease or severity in children with asthma. Ammonium was significantly lower in children with asthma when compared with controls.

KEYWORDS: Ammonium, asthma, exhaled breath condensate, pH

$\mathbf{A}$ sthma in childhood is common, conveys significant morbidity and has underlying airway inflammation [1-3]. Suppression of inflammation is considered to be important in controlling symptoms and attenuating airway remodelling. However, the ability to measure airway inflammation and to demonstrate modification by anti-inflammatory medicine is extremely limited in children. Pulmonary function is a poor surrogate for airway inflammation in childhood [4], and, although bronchoalveolar lavage and induced sputum have been used to assess airway inflammation in children, they are not acceptable repetitive measures. Exhaled nitric oxide (NO) is a useful adjunct to the clinical assessment of airway inflammation. However, its limitations are well documented, and NO alone does not represent a sufficiently robust marker of airway inflammation inchildren [5].

Exhaled breath condensate (EBC) assesses the inflammatory profile of low molecular weight solutes in exhaled air. Its collection is acceptable to young children and can be repeated regularly with their willing cooperation [6]. EBC in children, therefore, may be a valuable tool for measuring airway inflammation. In children with asthma, the technique has demonstrated increased leukotrienes, interleukin-4, 8-isoprostane, aldehydes and glutathione when compared with controls [7-10]. The effects of treatment on EBC in asthma include a reduction in nitrites in association with altitude in the Swiss Alps [11], and a reduction in cysteinyl leukotrienes, 8 -isoprostane, aldehydes and glutathione during systemic corticosteroid treatment of an acute exacerbation [10, 12]. However, there has usually been significant overlap between cases and controls, and no marker has, so far, demonstrated sufficient independence to assist with the diagnosis or treatment in children.

Acidification of airway surface lining fluid (ASL) raises pulmonary resistance by causing smooth muscle contraction [13], increasing mucous viscosity [14] and decreasing ciliary beat frequency [15], as well as directly causing bronchoconstriction [16] and altering the integrity of the epithelium [17]. The acid-base balance of ASL is only partly understood, and how this relates to the $\mathrm{pH}$ of $\mathrm{EBC}$ has not yet been established.
AFFILIATIONS

${ }^{*}$ Respiratory Medicine Unit, Western General Hospital, and

\#Dept of Respiratory and Sleep Medicine, Royal Hospital for Sick Children, Edinburgh, UK.

CORRESPONDENCE

S. Cunningham

Dept of Respiratory and Sleep Medicine

Royal Hospital for Sick Children

Sciennes Road

Edinburgh

EH9 1LF

UK

Fax: 441315360052

E-mail:

steve.cunningham@luht.scot.nhs.uk

Received:

September 102004

Accepted after revision:

May 032005 
Acidification can take place through an increase in free protons or a reduction in alkaline-buffering capacity. The cause of this increase in free protons has not been identified in vivo, but various pathways have been proposed, such as active excretion of protons by $\mathrm{H}^{+}$ATPase [18] and generation of hypochlorous acid by the reaction between hydrogen peroxide and chloride [19]. Probable ASL buffers include bicarbonate, proteins and ammonium. Therefore, ammonium production, by the enzyme glutaminase, is potentially an important source of buffer in determining ASL $\mathrm{pH}$. Glutaminase expression and activity is increased by low $\mathrm{pH}$ [20] and reduced by pro-inflammatory cytokines, including tumour necrosis factor- $\alpha$ and interferon- $\gamma$ [21]. Ammonium production by the lung is increased by dexamethasone in vitro [22] and in vivo [21], presumably via inhibition of pro-inflammatory cytokines.

The acidification of breath condensate has been assessed in inflammatory airway disorders [19, 23]. In adults with asthma, both $\mathrm{pH}$ and ammonium have been shown to be reduced in patients during acute exacerbations [21, 24]. In addition, adults with chronic asthma maintained on inhaled corticosteroids (ICS) have a higher condensate $\mathrm{pH}$ when compared with steroid-naïve patients [19]. Children with stable asthma have previously been demonstrated to have a lower EBC pH than controls [25, 26]; however, small numbers of children in these studies limited an assessment of the possible spectrum across the disease that is so commonly experienced in children with asthma. Hence, the aim of the current study was to assess a larger number of children spanning the spectrum of paediatric asthma, to elucidate whether $\mathrm{pH}$ and ammonium could represent useful markers of disease severity.

In addition, a recent study has demonstrated a reduction in cysteinyl leukotrienes and 8-isoprostane following systemic corticosteroids for an acute exacerbation in children [12]; however, no other EBC evaluation of acute asthma exacerbations in children has been made. Therefore, the current authors also aimed to assess whether children would demonstrate a similar change in EBC $\mathrm{pH}$ during treatment of an acute exacerbation to that seen in adults [24].

\section{METHODS}

The study was based in a university paediatric teaching hospital (Royal Hospital for Sick Children, Edinburgh, UK) and was in two parts: 1) a cross-sectional observational study of children with chronic asthma attending a hospital-based out-patient asthma clinic for routine review; and 2) a longitudinal study of children admitted to hospital with an acute exacerbation of asthma.

\section{Cross-sectional study}

In the cross-sectional study, children with a physician diagnosis of asthma attended an asthma clinic, and were on regular ICS, in addition to other asthma medication. Children were requested to provide details of their current medication and the number of symptom-free days (cough, wheeze or dyspnoea) in the previous 7 days. They were excluded during that visit if they had had a viral respiratory tract infection in the previous 7 days. Children were subdivided into one of five treatment steps based on their current asthma therapy (table 1), according to British Thoracic Society (BTS) guidelines [27], reflecting their disease severity. Leukotriene antagonists, released after the 1995 guidelines [27], were included as an alternative to salmeterol for the purposes of the study.

\section{Longitudinal}

Children admitted with an acute episode of asthma were assessed following stabilisation. An acute exacerbation was determined by wheeze, increased work of breathing, tachypnoea with/without desaturation in a child with a history of asthma, and no clinical evidence of lower respiratory tract infection (pyrexia $>38.4^{\circ} \mathrm{C}$, focal crepitations, pleuritic pain). All children required oral prednisolone $\left(2 \mathrm{mg} \cdot \mathrm{kg}^{-1}\right.$, maximum $40 \mathrm{mg}$ ) and regular inhaled bronchodilator. Oxygen saturation, heart rate and respiratory rate on arrival at the accident and emergency unit were noted. Children were then asked to participate, as soon as they felt comfortable, by providing an EBC sample for $\mathrm{pH}$ and ammonium measurement. Clinical observations and therapy required at the time of each measurement were noted.

\section{Controls}

Control children attended an orthopaedic fracture clinic (Royal Hospital for Sick Children, Edinburgh, UK) with a stable injury of $\geqslant 7$ days standing. These children did not have a history of respiratory illness in the previous 7 days, and they had no previous diagnosis or history suggestive of asthma. Five children attending the fracture clinic had a history of mild asthma requiring the intermittent use of inhaled $\beta_{2}$-agonist, and these patients were included in the asthma group under BTS step 1 (such patients are not normally seen in a hospitalbased asthma clinic).

\section{TABLE 1 British Thoracic Society treatment steps"}

\begin{tabular}{|c|c|c|c|c|}
\hline Treatment step & Short-acting $\beta_{2}$-agonist & ICS total daily dose $\mu \mathrm{g}$ & $\begin{array}{c}\text { Long-acting } \beta_{2} \text {-agonist or } \\
\text { leukotriene antagonist }\end{array}$ & Oral corticosteroids \\
\hline 1 & Yes & & No & No \\
\hline 2 & Yes & $\leqslant 400$ & No & No \\
\hline 3 & Yes & $\leqslant 800$ & Yes & No \\
\hline 4 & Yes & $>800$ & Yes & No \\
\hline 5 & Yes & $>800$ & Yes & Yes \\
\hline
\end{tabular}

ICS: inhaled corticosteroids. \#: ICS beclomethasone equivalent doses [27]. 


\section{$E B C$ collection and analysis}

EBC was collected using a commercially available condensing machine (Ecoscreen; Jaeger Viasys, Hoechberg, Germany). With this system, exhaled air is conducted through a lamellar condenser to a collection tube situated within a cooling cuff (cooled to $-10^{\circ} \mathrm{C}$ ). The collected sample is cooled but not frozen. Children provided a sample of EBC over a period of 5 min using tidal breathing and nose clips, until $\sim 500 \mu \mathrm{L}$ had been obtained. $\mathrm{pH}$ was measured using a handheld pH meter (phBoy; Camlab, Cambridge, UK) with a two-point calibration performed at the start of each session; samples were assessed immediately following condensate collection. Ammonium was measured using a solid state ion selective electrode and 3345 ion meter (Jenway, Dunmow, UK). The ion probe was inverted and $130 \mu \mathrm{L}$ of the sample was applied to this surface. A five-point standard curve of ammonium chloride solution (1,000 parts per million (ppm), $100 \mathrm{ppm}$, $10 \mathrm{ppm}, 1 \mathrm{ppm}$ and $0.1 \mathrm{ppm}$; Sigma, UK) was generated and had a lower limit of detection at $5.5 \mu \mathrm{M}$ (0.1 ppm); exponential extrapolation of data from the voltage recording was then performed. To calculate the coefficient of variation of the ammonium assay, 100 standards were assayed at 10 $(550 \mu \mathrm{M})$ and $100 \mathrm{ppm}(5,500 \mu \mathrm{M})$. The coefficients of variation for this analysis technique were $0.7 \%$ and $1.3 \%$, respectively.

\section{Lung function}

Following condensate collection, children performed spirometry (Vitalograph, Buckingham, UK) and peak flow measurements (Wright peak flow meter; Airmed Ltd, Harlow, UK), not including controls and children in the BTS step 1 group. The best of three performances was accepted and expressed as a per cent predicted value [28]. Samples were taken $\geqslant 4 \mathrm{~h}$ following any $\beta_{2}$-agonist.

\section{Statistics}

Spearman rank correlation, Mann-Whitney U-test and Kruskall Wallis were applied as appropriate. Data are presented as median (range), unless otherwise indicated.

\section{Ethics}

Ethical approval was granted by Lothian Health Research Ethics Committee (Edinburgh, UK). Parents were provided with an information leaflet and asked to provide written consent. Children were asked if they wished to participate.

\section{RESULTS}

\section{Cross-sectional study}

A total of 74 children with asthma were assessed (median (range) age 10.5 yrs (5-16); 54 males; 20 females). Median forced expiratory volume in one second (FEV1; \% predicted) at the time of condensate collection was $89 \%$ (range $41-134 \%$ ), with a significantly lower FEV1 \% pred in those receiving higher doses of regular treatment $(p=0.006)$. The children had a range of disease severity and spanned the BTS treatment steps, as follows: 1$) \mathrm{n}=5(7 \%) ; 2) \mathrm{n}=18(24 \%) ; 3) \mathrm{n}=28(38 \%)$; 4) $n=16(22 \%)$; and 5$) n=7(9 \%)$. A median (interquartile range) of $475 \mu \mathrm{L}(300-550)$ of EBC fluid was collected.

There was a significant association between the number of symptom-free days in the past 7 days and both FEV1 \% pred $(\mathrm{r}=0.335 ; \mathrm{p}<0.005)$ and BTS treatment step $(\mathrm{r}=-0.367$; $p<0.001$ ), confirming that children with worse lung function and higher levels of treatment had more regular symptoms.

Forty-seven children without asthma provided control samples (median (range) age 10 yrs (6-14); 33 males; 14 females).

No significant difference was identified between the $\mathrm{pH}$ of EBC in children with stable asthma (pH median (range) 6.05 (4.70-7.60) ) compared with controls ( $\mathrm{pH}$ median (range) 5.90 (5.00-7.30); $\mathrm{p}=0.139$; fig. 1). There was no correlation between $\mathrm{pH}$ and children's age, height, FEV1, forced expiratory flow at $50 \%$ of the forced vital capacity (FEF50) or peak expiratory flow rate (PEFR), or an association with the number of symptomfree days. Children with stable asthma used a median (interquartile range) $1,000 \mu \mathrm{g}(500-2,000)$ of ICS (beclomethasone diproprionate equivalent). There was no significant correlation between the dose of ICS and EBC $\mathrm{pH}(\mathrm{r}=0.118$; $\mathrm{p}=0.11)$.

Ammonium $(\mu \mathrm{M})$ was significantly lower in the EBC of children with asthma (median (range) $258 \mu \mathrm{M}$ (61-721)) when compared with control children $(428 \mu \mathrm{M}(112-1,300) ; \mathrm{p}<0.001)$. There was no correlation between ammonium and children's age, height, FEV1, FEF50 or PEFR, or an association with the number of symptom-free days. There was a nonsignificant correlation between ammonium and $\mathrm{pH}(\mathrm{r}=-0.253$; $\mathrm{p}=0.052)$.
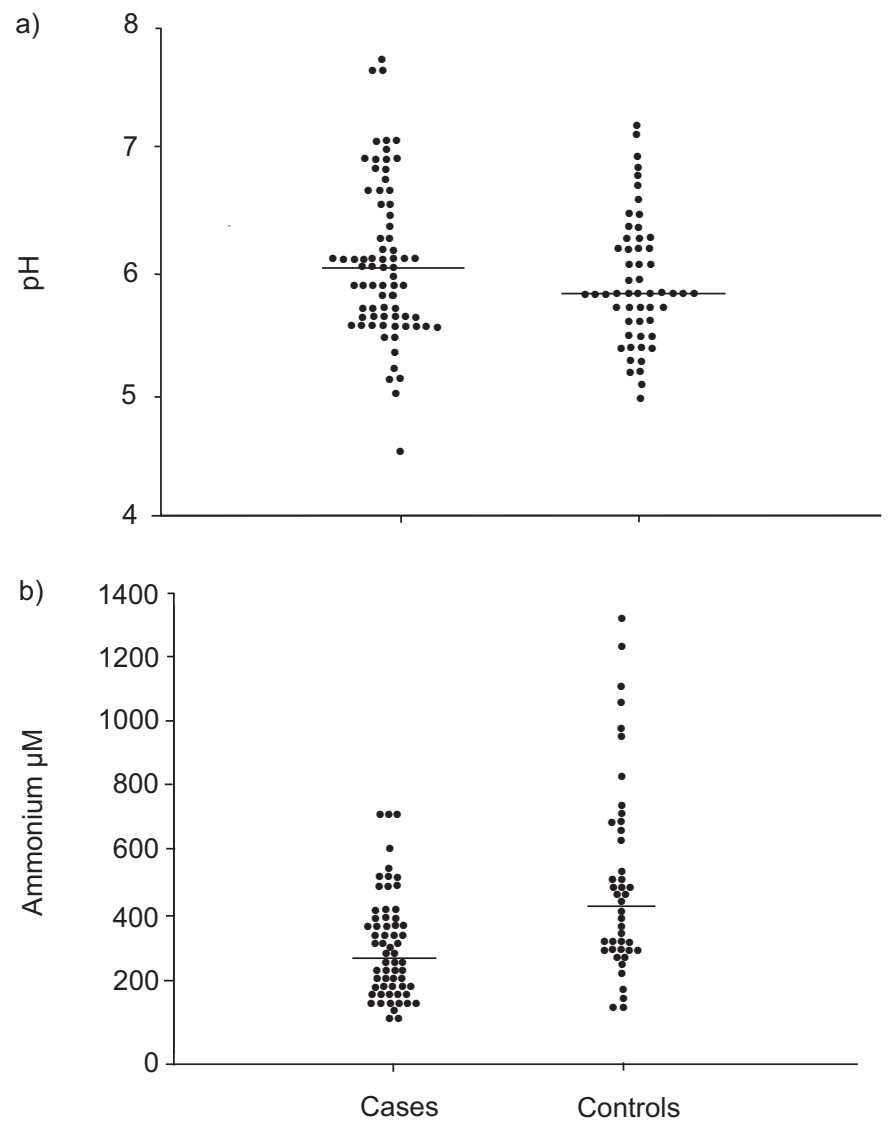

FIGURE 1. a) $\mathrm{pH}$ in children with asthma $(n=74)$ compared with controls $(n=47 ; p=0.139) ;$ and $b)$ ammonium in children with asthma compared with controls $(p<0.001)$. Horizontal bars represent the median. 


\section{Longitudinal study}

Eight children (five males) were assessed during an admission with acute asthma (mean age $8.5 \mathrm{yrs}$ ). Three children were cared for in a high-dependency area and five in a ward area. Children provided a mean of three samples during their stay, taken $\sim 24 \mathrm{~h}$ apart.

As the time in hospital increased, there was a significant improvement in oxygen saturation in air $(r=0.578 ; p=0.005)$ and respiratory rate $(\mathrm{r}=-0.574 ; \mathrm{p}=0.005)$. This clinical improvement was not reflected in terms of $\mathrm{pH}(\mathrm{r}=-0.026$; $\mathrm{p}=0.908)$ or ammonium $(r=-0.221 ; p=0.363)$. The initial samples of EBC taken at a mean of $22 \mathrm{~h}$ post admission (and $25 \mathrm{~h}$ after oral prednisolone) had a median (range) $\mathrm{pH} 6.3$ (5.8-6.7) and ammonium $556 \mu \mathrm{M}(245-1,153)$. This initial $\mathrm{pH}$ was similar to the median value in the current stable group. In adults, EBC $\mathrm{pH}$ at $48 \mathrm{~h}$ after systemic corticosteroids also approached that of stable patients [24]. The median first ammonium level, however, was higher than the studied stable asthma population, and much higher than in adult exacerbation studies [21]. All ammonium analyses were performed at the same time. Oral contamination of EBC with ammonia has been reported as insignificant [29]; however, the study was performed in healthy subjects without respiratory disease, and it is possible that children who are breathless during an exacerbation are prone to contamination; hence, this requires further consideration. Three children had particularly high levels of ammonium during their exacerbation $(>1,000 \mu \mathrm{M})$, with the other five children with exacerbations experiencing levels seen in stable asthma children, which may represent contamination or an increased exacerbation-buffering capacity not seen in adults. The current authors' acute exacerbation results would suggest that either there is faster recovery from exacerbation in children with acute asthma or that they do not experience acidification of the airway in the same manner demonstrated in adult asthmatics.

\section{DISCUSSION}

The current study has demonstrated that ammonium in EBC was lower in children with stable asthma when compared with controls. However, $\mathrm{pH}$ was not significantly different between controls and children with stable asthma, nor did it reflect asthma severity in this group. Contrary to studies in adults, neither $\mathrm{pH}$ nor ammonium was reduced in children with an acute asthma exacerbation, nor did they demonstrate a consistent change during the course of treatment for the exacerbation.

Acidification of the airway has important physiological effects, such as bronchoconstriction, increased mucous viscosity, etc. As these effects may contribute to the pathophysiology of asthma, identifying which populations have increased the acidification of ASL has received much attention. The acidbase balance in the airway and noninvasive measurement methods have formed part of this investigation. Asthma and cystic fibrosis (CF) have both been considered. Five studies have assessed EBC $\mathrm{pH}$ in patients with asthma [19, 2426, 30], and, of these, one adult [19] and one paediatric study [26] have demonstrated lower $\mathrm{pH}$ in stable asthma patients when compared with controls. In the adult study [19], this difference was only present in steroid-naive adult asthmatics with moderate disease; the EBC $\mathrm{pH}$ in stable adult asthma patients treated with ICS was no different from that of controls. In one paediatric study [25], the EBC $\mathrm{pH}$ of 20 patients with asthma was able to significantly differentiate mild from moderate/severe asthmatics, although there was no association between $\mathrm{pH}$ and FEV1. In another paediatric study [26], there was no significant difference between the EBC $\mathrm{pH}$ of 23 asthmatic children compared with nine controls when samples were de-aerated; however, a difference was identified when the values prior to de-aeration were considered $(\mathrm{p}<0.05)$. The first report of $\mathrm{EBC} \mathrm{pH}$ in adults [24] did not identify a statistical difference between stable asthma patients and controls. A recent study in adults [30] did not identify a difference in the EBC $\mathrm{pH}$ of mild asthmatic adult patients who were steroid naïve. Therefore, the current results are consistent with adult studies (and with the lack of initial association in one paediatric study), concluding that there is not a significant difference between EBC $\mathrm{pH}$ in chronic stable treated asthma patients when compared with controls. In addition, the present study did not demonstrate any differences within the range of asthma severity, but this contrasts with the report by CARPAGNANO et al. [26] who used the same equipment and methodology as the current authors. The reasons for this difference are unclear, since, in the current study, FEV1 was associated with worse asthma and more treatment, and, in the study by CARPAGNANO et al. [26], severe asthmatics had lower $\mathrm{pH}$, although this was not reflected in terms of lower FEV1, as might be expected. EBC $\mathrm{pH}$, like exhaled NO, appears to be most sensitive when used to identify steroid-naïve asthma patients, and, like exhaled $\mathrm{NO}$, is less able to differentiate different degrees of treated asthma [30, 31].

The longitudinal assessment of $\mathrm{pH}$ during an asthma exacerbation has only been previously reported in one adult study [24]. This study of repeated EBC $\mathrm{pH}$ measurements in five adult patients with acute asthma concluded that treatment with systemic corticosteroids was associated with a significant increase in EBC pH over time, such that values approached stable asthma values at $48 \mathrm{~h}$. The current authors' evaluation of eight patients with an acute asthma exacerbation, with the first EBC samples taken within a similar timescale to the study by HuNT et al. [24], did not demonstrate a consistent trend. In the study by HuNT et al. [24], samples taken $\sim 40 \mathrm{~h}$ after systemic corticosteroids demonstrated EBC $\mathrm{pH}$ ranging 4.5-7.5 in four adult patients. At $40 \mathrm{~h}( \pm 6)$ post systemic corticosteroids, the children in the present cohort had an EBC pH range of 5.3-6.8, which was much tighter than that seen in adults, but, despite this, no overall trend was seen. The current authors would suggest that EBC pH in children with acute asthma does not appear to be a useful tool to monitor progress over time post systemic corticosteroids.

As EBC $\mathrm{pH}$ has been postulated to be an important indicator of airway disease, the counterbalance alkalising buffer molecules in the airway have also received interest. Ammonium has been of particular interest because of the effect of corticosteroids [22, 32] and asthma-related cytokines [33] on glutaminase action (and, hence, ammonium production). In patients with asthma, the balance of inflammatory downregulation and corticosteroid upregulation of glutaminase activity are considered to be important in determining airway ammonium levels. 
The current study provides the first report of EBC ammonium values in patients with chronic stable asthma. These patients have significantly lower levels of ammonium than are seen in control patients. There is overlap with controls (fig. 1b) and no association between ammonium values and disease severity, and, therefore, it is unlikely that EBC ammonium could be relied upon as an independent inflammatory marker in asthma. HUNT et al. [21] have previously reported low levels of EBC ammonium from single samples in adults with acute asthma when compared with controls. Ammonium values in the current acutely ill, longitudinally assessed asthma patients were higher than control values and much higher than those reported by HunT et al. [21]. However, the results in their control group (median (range) $327 \mu \mathrm{M}(14-1,220)$ ) demonstrated a similar spread of results to the current authors' controls (median (range) $428 \mu \mathrm{M}(112-1,300)$ ), so it is probable that the techniques are consistent. It is possible that glucocorticoid upregulation is more important than inflammatory suppression of glutaminase in children with asthma, although this is speculation and would require paediatric airway cellculture evaluation. Low EBC ammonium values in children and adults with CF both during stable periods and during exacerbations have been reported [34]; in particular, children with CF during a respiratory exacerbation did not experience very high levels of EBC ammonium, which is suggestive of oral contamination. In addition, a study in healthy adults without respiratory disease reported oral contamination of EBC by oral ammonia to be of negligible importance [29]. Although the contamination of samples by acutely breathless asthmatic children cannot be excluded, it is not considered as a probable cause of the results presented, given the current authors' success with acutely unwell children with CF [34]. The range of EBC ammonium results demonstrated in this study and that of HuNT et al. [21] would suggest that larger numbers of patients may be needed in future studies of EBC ammonium.

De-aeration of EBC with an inert gas (i.e. argon) increases $\mathrm{pH}$. Carbon dioxide is the principle acidifier within air that is removed during the de-aeration process, and yet reduction of exhaled carbon dioxide by $50 \%$ has no significant effect on EBC $\mathrm{pH}$ [35], and so the role of de-aeration remains unclear. Deaerating a selection of the present samples with argon $(n=38)$ identified a strong correlation between $\mathrm{pH}$ using the two methodologies $(\mathrm{r}=0.589 ; \mathrm{p}<0.0001)$; this close correlation between the $\mathrm{pH}$ of aerated and deaerated samples has been confirmed by others [25]. Rosias et al. [25] have demonstrated no change in correlation between lung function or exhaled NO in children with asthma pre- to post-de-aeration, and OJOO et al . [30] have noted significant changes in airway $\mathrm{pH}$ despite non de-aeration. After collection, there are changes in EBC $\mathrm{pH}$ with time and, therefore, samples need to be assessed immediately (as was chosen in the current study) [30], left to naturally deaerate over 2-3 h [25] or de-aerated [24].

This study has demonstrated that ammonium in exhaled breath condensate was lower in children with stable asthma when compared with controls, although overlap between the groups exists. However, $\mathrm{pH}$ did not help to differentiate children with stable asthma from controls, nor did it reflect asthma severity in this group. Contrary to studies in adults, neither $\mathrm{pH}$ nor ammonium was reduced in children with acute asthma, nor did they demonstrate a consistent change during the course of treatment for the exacerbation.

\section{REFERENCES}

1 Warke TJ, Fitch PS, Brown V, et al. Exhaled nitric oxide correlates with airway eosinophils in childhood asthma. Thorax 2002; 57: 383-387.

2 Gibson PG, Simpson JL, Hankin R, Powell H, Henry RL. Relationship between induced sputum eosinophils and the clinical pattern of childhood asthma. Thorax 2003; 58: 116-121.

3 Lemanske RF. Inflammation in childhood asthma and other wheezing disorders. Pediatrics 2002; 109, Suppl. 2, 368-372.

4 Chang AB, Harrhy VA, Simpson J, Masters IB, Gibson PG. Cough, airway inflammation, and mild asthma exacerbation. Arch Dis Child 2002; 86: 270-275.

5 Gibson PG, Henry RL, Thomas P. Noninvasive assessment of airway inflammation in children: induced sputum, exhaled nitric oxide, and breath condensate. Eur Respir J 2000; 16: 1008-1015.

6 Baraldi E, Ghiro L, Piovan V, Carraro S, Zacchello F, Zanconato S. Safety and success of exhaled breath condensate collection in asthma. Arch Dis Child 2003; 88: 358-360.

7 Csoma Z, Kharitonov SA, Balint B, Bush A, Wilson NM, Barnes PJ. Increased leukotrienes in exhaled breath condensate in childhood asthma. Am J Respir Crit Care Med 2002; 166: 1345-1349.

8 Shahid SK, Kharitonov SA, Wilson NM, Bush A, Barnes PJ. Increased interleukin- 4 and decreased interferon-gamma in exhaled breath condensate of children with asthma. Am J Respir Crit Care Med 2002; 165: 1290-1293.

9 Baraldi E, Ghiro L, Piovan V, et al. Increased exhaled 8isoprostane in childhood asthma. Chest 2003; 124: 25-31.

10 Corradi M, Folesani G, Andreoli R, et al. Aldehydes and glutathione in exhaled breath condensate of children with asthma exacerbation. Am J Respir Crit Care Med 2003; 167: 395-399.

11 Straub DA, Ehmann R, Hall GL, et al. Correlation of nitrites in breath condensates and lung function in asthmatic children. Pediatr Allergy Immunol 2004; 15: 20-25.

12 Baraldi E, Carraro S, Alinova R, et al. Cysteinyl leukotrienes and 8-isoprostane in exhaled breath condensate of children with asthma exacerbations. Thorax 2003; 58: 505-509.

13 Ricciardolo FL, Rado V, Fabbri LM, Sterk PJ, Di Maria GU, Geppetti P. Bronchoconstriction induced by citric acid inhalation in guinea pigs: role of tachykinins, bradykinin, and nitric oxide. Am J Respir Crit Care Med 1999; 159: 557-562.

14 Holma B. Influence of buffer capacity and $\mathrm{pH}$-dependent rheological properties of respiratory mucus on health effects due to acidic pollution. Sci Total Environ 1985; 41: 101-123.

15 Clary-Meinesz C, Mouroux J, Cosson J, Huitorel P, Blaive B. Influence of external $\mathrm{pH}$ on ciliary beat frequency in human bronchi and bronchioles. Eur Respir J 1998; 11: 330-333. 
16 Aris R, Christian D, Sheppard D, Balmes JR. Acid foginduced bronchoconstriction. The role of hydroxymethanesulfonic acid. Am Rev Respir Dis 1990; 141: 546-551.

17 Giddens WE, Fairchild GA. Effects of sulfur dioxide on the nasal mucosa of mice. Arch Environ Health 1972; 25: 166-173.

18 Inglis SK, Wilson SM, Olver RE. Secretion of acid and base equivalents by intact distal airways. Am J Physiol Lung Cell Mol Physiol 2003; 284: L855-L862.

19 Kostikas K, Papatheodorou G, Ganas K, Psathakis K, Panagou P, Loukides S. pH in expired breath condensate of patients with inflammatory airway diseases. Am J Respir Crit Care Med 2002; 165: 1364-1370.

20 Labow BI, Souba WW, Abcouwer SF. Mechanisms governing the expression of the enzymes of glutamine metabolism: glutaminase and glutamine synthetase. J Nutr 2001; 131: Suppl. 9, S2467-S2474.

21 Hunt JF, Erwin E, Palmer L, et al. Expression and activity of pH-regulatory glutaminase in the human airway epithelium. Am J Respir Crit Care Med 2002; 165: 101-107.

22 Ardawi MS. Glutamine metabolism in the lungs of glucocorticoid-treated rats. Clin Sci (Lond) 1991; 81: 37-42.

23 Tate S, MacGregor G, Davis M, Innes JA, Greening AP. Airways in cystic fibrosis are acidified: detection by exhaled breath condensate. Thorax 2002; 57: 926-929.

24 Hunt JF, Fang K, Malik R, et al. Endogenous airway acidification. Implications for asthma pathophysiology. Am J Respir Crit Care Med 2000; 161: 694-699.

25 Rosias PP, Dompeling E, Dentener MA, et al. Childhood asthma: exhaled markers of airway inflammation, asthma control score, and lung function tests. Pediatr Pulmonol 2004; 38: 107-114.
26 Carpagnano GE, Barnes PJ, Francis J, Wilson N, Bush A, Kharitonov SA. Breath condensate $\mathrm{pH}$ in children with cystic fibrosis and asthma. Chest 2004; 125: 2005-2010.

27 British Thoracic Society. The British Guidelines on Asthma Management 1995 Review and Position Statement. Thorax 1997; 52: Suppl. 1, S1-S20.

28 Rosenthal M, Bain SH, Cramer D, et al. Lung function in white children aged 4 to 19 years: I- Spirometry. Thorax 1993; 48: 794-802.

29 Wells K, Vaughan J, Pajewski TN, et al. Exhaled breath condensate $\mathrm{pH}$ assays are not influenced by oral ammonia. Thorax 2005; 60: 27-31.

30 Ojoo JC, Mulrennan SA, Kastelik JA, Morice AH, Redington AE. Exhaled breath condensate $\mathrm{pH}$ and exhaled nitric oxide in allergic asthma and in cystic fibrosis. Thorax 2005; 60: 22-26.

31 Godfrey S. Ups and downs of nitric oxide in chesty children. Am J Respir Crit Care Med 2002; 166: 438-439.

32 Abcouwer SF, Lukaszewicz GC, Souba WW. Glucocorticoids regulate glutamine synthetase expression in lung epithelial cells. Am J Physiol 1996; 270: L141-L151.

33 Sarantos P, Abouhamze A, Abcouwer S, Chakrabarti R, Copeland EM, Souba WW. Cytokines decrease glutaminase expression in human fibroblasts. Surgery 1994; 116: 276-283.

34 MacGregor G, Cain D, Ellis S, et al. Low ammonium levels in exhaled breath condensate in cystic fibrosis adults and children. Am J Respir Crit Care Med 2003; 167: A916.

35 Vaughan J, Ngamtrakulpanit L, Pajewski TN, et al. Exhaled breath condensate $\mathrm{pH}$ is a robust and reproducible assay of airway acidity. Eur Respir J 2003; 22: 889-894. 